\title{
Primary Health Care and Hospital Management During COVID-19: Lessons from Lombardy
}

\author{
Barbara Plagg (1D ${ }^{1,2}$ \\ Giuliano Piccoliori' \\ Jörg Oschmann ${ }^{3}$ \\ Adolf Engl' \\ Klaus Eisendle $\mathbb{D}^{1,4}$ \\ 'Institute of General Practice and Public \\ Health - College of Health Care \\ Professions Claudiana, Bolzano, Italy; \\ ${ }^{2}$ Free University of Bozen/Bolzano, \\ Bolzano, Italy; ${ }^{3}$ Institute of Cultural and \\ Social Anthropology, Ludwig Maximilians \\ University, Munich, Germany; ${ }^{4}$ Central \\ Hospital Bolzano/Bozen, Bolzano, Italy
}

\begin{abstract}
The pandemic due to SARS-CoV-2 tested the resilience of health systems worldwide. The outcome of the pandemic is impacted by health management choices made over the course of the disaster, which in turn are strongly dependent on the underlying healthcare system - as mirrored by the fact that regional pandemic experiences differ considerably: In Italy (a country most impacted by the COVID-19 outbreak), infection and mortality rates vary vastly between regions, with Lombardy - a comparatively well-equipped region with regard to hospitals and centers of scientific excellence - being amongst the worst-affected areas. Within this article, we focus on the challenges within primary health care and hospital organization, cooperation between primary and specialist care, and access to health care services: In Lombardy, neglected primary health care with a comparatively low availability of general practitioners (GPs) per inhabitant, the initial prioritization of hospitals during the pandemic while neglecting primary health care in terms of personal protective equipment (PPE), the lack of testing resources, and a failure to achieve coordinated support contributed to a quick overburdening of hospitals, where the dissolution of traditional departments into "macro-areas" may favor nosocomial infections during an ongoing pandemic. Neither specialized medicine nor privatization, but rather flexible public healthcare services working in consistent cooperation with GPs, show better efficiency in containing viral spread and managing patients. Strengthening the primary health care sector with regard to human and technical resources and supporting the coordination between the different levels of health care providers help to avoid overcrowded hospitals, while protecting patients and health care workers during large-scale health emergencies. Overall, further in-depth analysis of structural determinants is needed in order to develop more-resilient and integrative health care systems.
\end{abstract}

Keywords: COVID-19, disaster management, primary health care, intensity of care hospitals, continuity of care, integration of care

\section{Introduction}

Italy has been among the countries most impacted by the coronavirus outbreak, making it one of the countries with the highest fatality rates worldwide. ${ }^{1}$ Indeed, in the course of the pandemic, fatality rates have differed among countries and continents, and these differences are influenced by determinants such as structural management, political decisions, timeline of health management choices, availability of resources (such as ICU beds and ventilators) and population-specific characteristics such as demography (eg, age, population density, background diseases, lifestyle), cultural peculiarities (eg, socialization, clustering, economic activity), perception, and the implementation of hygienic measures. ${ }^{2-4)}$ However, not only between countries, but also within different
Correspondence: Barbara Plagg Email barbara.plagg@unibz.it 
regions of the same country, different infection and lethality rates became apparent, as the case of Italy impressively illustrates: During the first months of the pandemic (MarchMay 2020), Lombardy had an excess mortality of $+111.8 \%$, while for neighboring Veneto $+19.4 \%$ was reported. ${ }^{5}$ A difference deserving a closer look, since due to the novelty and recency of the situation, a careful analysis of structural determinants represents an essential part of a future-oriented disaster management approach. Effectively, the development of a resilient health care concept is of high public health relevance, since health threats will continue to be a global challenge as both acute and chronic conditions are increasing due to environmental hazards, anthropogenic activities, and social disparities. ${ }^{6}$ In the aftermath of the pandemic, the rearrangement of health care services based on the analysis of the pandemic experiences takes on increasing sociopolitical importance in Italy as well as in other countries. With the present article, we illustrate how determinants within primary health care and hospital management had an important impact on the epidemic outcome and wish to stimulate further research in order to develop resilient models of care and reduce the impact of future disasters.

\section{Primary Health Care: Collapse of the First Line of Defense}

Italy has a highly decentralized health care system organized on a relatively autonomous regional basis with territorial inequalities, progressive privatization, and rather little national coordination amongst its 20 regions. $^{7}$ Specialists and other physicians work as salaried employees of the National Health Service (Servizio Sanitario Nazionale), while GPs work as private contractors, generally in solo practices, and are paid on a capitation basis. ${ }^{8}$ Due to the federalist fragmentation, the regions perform differently in terms of service delivery. ${ }^{9}$ While gaps in service provision and health system performance between the southern and the northern parts of the country persist, Lombardy, for instance, has been increasingly investing in specialist medical care. 9,10

Overall, Italy has neglected its primary health care system in recent years with an availability of 89 GPs per 100,000 inhabitants, numbers well below compared to Germany (167.4) and France (155.5). ${ }^{11}$ Lombardy, for instance, has much of all (medical) resources, but with a total of $6143 \mathrm{GPs}$, it has only 0.74 GP per 1000 inhabitants, with $78 \%$ being older than 55 years by $2019 .{ }^{12}$ The initial focus on hospitals during COVID-19 while leaving in many regions and states primary care physicians without testing resources, adequate
PPE, structural support, and power is impressively mirrored in the mortality statistics since the outbreak of the pandemic: $^{13-16}$ to date (22.02.2021) 119 of 328 of the Italian doctors who died in the relevant time-frame were GPs. ${ }^{17}$ Working on the frontlines, GPs are frequently exposed to the virus and may on one hand themselves be affected by the disease and therefore be unable to work; on the other hand, any health worker may be — if not adequately protected by the appropriate PPE - the source of community spread themselves. ${ }^{18}$ Consequently, some GPs reduced patient visits due to the lack of equipment, avoided home visits, and turned to video consultations to reduce patient flow and limit infectious exposures. ${ }^{19}$ This dynamic created an additional care vacuum at the territorial level of primary care where it came to a backlog in the management of both acute and chronic illness. ${ }^{19-21}$ The lack of cooperation between the primary health sector and other public and private health care suppliers and hospitals as well as bureaucratic barriers became an additional problem in Lombardy as well as in other regions and states — as it made the coordinated and immediate management of the emergency slow and hampered. ${ }^{22,23}$ Eventually, the problems in the primary health care sector due to both years of cost-cutting and neglect in equipment and support led to a rapid overcrowding of hospitals during the national emergency.

It is known that large proportions of Italians use medical emergency structures without actually meeting the definition of an emergency. According to the Italian Association for Emergency Medicine, 15\% of 24 million people accessing Italian emergency rooms every year are classified as "non-urgent". 20 In Lombardy, "white" and "green" codes account for $70 \%$ of all incoming ER patients. ${ }^{24}$ As overcrowded conditions and incidence of infectious disease are associated, crowding in ERs may have additionally promoted viral spreading. ${ }^{25,26}$ And eventually, even well-equipped hospitals cannot cope with an influx of patients on a pandemic scale. Effectively, simply having a high number of available ICU beds or increasing them in local hotspots without appropriate staff and strengthening of the primary care sector is not the solution and may paradoxically result in increased mortality, since the better response is to treat patients outside emerging hotspots in order to keep ICU loads below their maximum capacity. ${ }^{27}$ Indeed, a direct comparison between Lombardy (mortality COVID-19 per 100,000 inhabitants: 129.3) and neighboring Veneto (mortality COVID-19 per 100,000 inhabitants: 26.4) during the first months of the pandemic illustrates the impact of different structural decisions: 
While Lombardy prioritized hospital screening, Veneto tried to intercept COVID-19 patients before their referral to hospitals. ${ }^{28}$ Eventually, Lombardy hospitalized $66 \%$ of all COVID-19 patients while Veneto hospitalized 20\%. ${ }^{25}$ This high rate of hospital-based patient care is a direct consequence of reduced primary care and territorial health services. Moreover, the early prioritization of hospitals directly bounced back to nursing and retirement homes - also hotspots of the pandemic: The COVID-19 related mortality rate between February 1st and May 5th 2020 was $3.1 \%$ in Italian nursing homes. ${ }^{26}$ During the first weeks of the pandemic, nursing homes were not equipped with sufficient Personal Protection Equipment (PPE), and national procedures did not foresee testing of people in care homes. ${ }^{30}$ As hospitals were increasingly running out of beds, people from the nursing homes could no longer be admitted. On the contrary: In order to free up hospital beds in Lombardy, patients with COVID-19 were sent from hospitals to retirement homes, thus potentially triggering additional chains of infection within the high-risk group. ${ }^{31}$ Ultimately, of course, Italy, and in particular Lombardy, started with a disadvantage as it had more initial cases but the course of the pandemic is strongly influenced by the structural determinants of the health care context rather than by singularly bad fate. With a structurally strengthened primary health care system, embedded in a coordinated cooperation of public and private health care structures and supported by nursing staff, a higher number of non-critical patients could have been monitored at home.

\section{"Intensity of Care": Hospital Organization and Macro-Areas}

The number of hospital beds in Italy has been declining for years (7.2 beds per 1000 people in 1990; 2.8 beds per 1000 people in 2017) and is lower than the European average. $^{32,33}$ Generally, health spending in Italy is with 2523 Euro per capita 12\% lower than the EU average of 2887 Euro in $2017 .{ }^{34}$ However, while these conditions doubtlessly lead to an increased shortage of resources under a pandemic situation, the heavily hit region of Lombardy is with 3.0 beds per 1000 people (acute: 3.1 ; non- acute: 0.7$)$ a region with a rather high availability compared to Italy's mean. ${ }^{29}$ Indeed, Lombardy is comparatively well equipped and, compared to the rest of Italy, particularly well endowed with hospitals and centers of scientific excellence (public hospital trusts: 27, institutes for scientific research: 26$):{ }^{33}$ A status which in addition to the misfortune of having had particularly many initial cases of infection - is worth a closer look since Lombardy features high mortality rates both for the general population and for doctors. ${ }^{28}$

In the recent tension between cutbacks and the adoption of financial recovery plans ("Piani di Rientro") due to the indebtedness of some regions, Tuscany, followed by Lombardy, Liguria, and Emilia-Romagna, reorganized hospitals according to the "intensity of care" principle in 2005. The so called "ospedale per intensità di cura" are no longer organized into departments according to medical discipline, but into homogeneous "macro"-areas where patients with converging care needs are allocated in homogenized areas. ${ }^{35}$ Consequently, the different professionals revolve around the patient who is hospitalized according to his/her clinical instability and the complexity of care. While consistent and scientifically valid evidence on the effects of "intensity of care" is still missing, within a SWOT analysis from 2012, medical doctors name the high turnover of patients between the macro-areas as a central weakness of this system, as well as role conflicts among the professional operators who move autonomously between the areas and the risk of diminished continuity of care. ${ }^{36}$ Nurses additionally underlined that overcrowding in macro-areas may endanger patients as well as medical and nursing staff. ${ }^{36}$ A study from central Italy within the first months of COVID-19 showed a higher prevalence of SARS-CoV-2 amongst HWs. ${ }^{37}$ Overall, besides an expected higher jobrelated-risk of infection, the organizational form of the hospital must contribute to the improvement of pandemic management in terms of infection reduction. For this reason, the dissolution of departments may not be the best option in terms of disaster management, since the higher turnover of patients and staff may favor a higher rate of nosocomial infections and viral spread, while role conflicts may hamper flexible cooperation and shared decision-making during disasters. Subdivision into smaller autonomous organizational units might be more expensive, but may provide protection from extensive viral spread within the context of a pandemic. However, reliable data on the performance of "intensity of care" hospitals under pandemic pressure is still pending and in need of further evaluation.

\section{Between Private and Public Healthcare Services: Access to Care}

For Italy, a substantial amount of inequity in health service use because of socioeconomic status has been reported, with 
a significant amount of pro-rich inequity in specialist care, diagnostic services, and basic medical tests, and pro-poor inequity in the use of primary health care. ${ }^{38}$ Eventually, despite full coverage for basic medical services, $7 \%$ of Italians report unmet needs for medical care in 2015 compared to the EU average of $4 \% .{ }^{34}$ Most of the unmet medical needs are attributable to care being too expensive. ${ }^{39}$ And while the healthcare sector - especially in Lombardy — became increasingly privatized and specialized, it has been shown that greater spending on the public delivery of health services corresponds to faster reductions in avoidable mortality rates, while spending on the private sector has no effect on avoidable mortality rates. ${ }^{40}$ In times of a pandemic, privatization policies may reduce the countries' ability to cope with a rapidly-spreading infectious disease such as COVID-19. ${ }^{41}$ Indeed, a study of the United Nations Development Program (UNDP) looking at the effect of healthcare privatization on COVID-19 found that a $10 \%$ increase in private health expenditure related to a $4.3 \%$ increase in COVID-19 cases and a $4.9 \%$ increase in COVID-19 related mortality. ${ }^{41}$ This has, however, been evident before the pandemic, since the private healthcare systems appeared to fail in addressing infectious diseases such as TB. ${ }^{42}$ In addition it has been shown that social determinants of health such as poverty, physical environment, and ethnicity can have a considerable effect on COVID-19 outcomes - social factors which in turn have a crucial influence on individual access to health services. ${ }^{43-45}$ In view of this, a decentralized NHS with a significant portion of privatized healthcare delivery with short-term benefits such as reduced costs and shorter waiting times must carefully be weighed against the negative impact of privatization on rapidly-spreading infectious diseases. ${ }^{36}$ This is especially important since the current pandemic is unlikely to be the last as both acute and chronic threats due to environmental hazards and social disparities are increasing. ${ }^{6,46}$

\section{Integration and Continuity of Primary and Specialist Care}

Since healthcare is a highly dynamic process, multidisciplinary approaches and strategies based on integrated and continuous care can overcome fragmentation by improving health system performance and reap the greatest gain in population health. ${ }^{47}$ Especially during disasters, healthcare providers are required to integrate into the larger, nonmedical multidisciplinary disaster response in order to operate safely and efficiently, either in a hospital or in their solo practices. ${ }^{47}$ During the current pandemic, an Italian study investigated the potential of integrated care pathways (ICP) to manage COVID-19 cases referred to the emergency department within structured and multidisciplinary care plans and reported that the ICP adoption during a well-defined interval of time in the emergency department resulted in a remarkable reduction of COVID19-related mortality (before $60 \%$ vs after 23.2\%). Capalbo et al illustrated that (early) health management choices with regard to integrated care had a relevant impact, since the early and appropriate treatment of symptomatic patients had been possible together with the strengthening of home management. ${ }^{4}$ While further evidence regarding the multisectoral and multidisciplinary cooperation during COVID-19 is needed as part of the disaster analysis, it is known that even outside disaster situations, most health systems do not take fully take advantage of the potential synergy offered by collaborative strategies between primary and specialist care and organizational systems have frequently failed to reflect the interlocking nature of different areas. ${ }^{4,48}$ As the aftermath of the recent pandemics provides an opportunity to build more-resilient health systems and since increasing pressure on health systems due to demographic, social, economic, and technological trends require, in any event, the moreeffective collaboration between the different health care sectors, developing models to strengthen integrated and multisectoral care has become an increasing public health urgency. ${ }^{4}$

\section{Conclusion}

The pandemic due to SARS-CoV-2 tested the resilience of health systems worldwide. The outcome of the pandemic is impacted by health management choices made over the course of the disaster, which in turn are strongly dependent on the underlying healthcare system - as mirrored by the fact that regional pandemic experiences differed considerably. In the aftermath of the pandemic, a careful analysis of health systems, organizational weaknesses, and structural pitfalls is necessary in order to develop integrative and resilient models of care. As a matter of course, different and multiple factors fuse and interact together within the context of a disaster, adding up to the complexity of the crisis. In the present article we specifically focused on the challenges within primary health care and hospital organization, cooperation between primary and specialist care, and access to health care services, while leaving additional factors such as other public health services (for instance primary prevention, health literacy, etc.), community knowledge, and populationspecific characteristics and cultural behaviors aside. Indeed, 
disaster management analysis is complex and requires an interdisciplinary approach. Regarding COVID-19, we are still in the disaster analysis phase, where further and more indepth analyses are needed as they represent an important basis for decision-making.

Overall, the pandemic has illustrated that specialized medicine alone cannot cope with an epidemic, but rather flexible and cooperating hospitals working in consistent cooperation with primary medical care show better efficiency in containing viral spread and in managing patients. Indeed, disaster management in the context of a health crisis is dependent on both the primary care sector and hospital management, as well as on the cooperation between the two entities and other stakeholders in health services. In order to face large-scale health emergencies and develop resilient models of health care, it remains thus of major importance to develop sustainable models of health care without cutting corners on patients' and health care workers' safety, by i) strengthening the primary care sector with regard to human and technical resources in order to identify and isolate cases early and avoid overcrowded ERs while protecting patients and health care workers, ii) reintroducing physically segregated independent departments with dedicated workforces to avoid viral spread and multi-drug resistant pathogens, iii) better coordination of the decentralized and fragmented NHS between the regions, iv) supporting and controlling the cooperation between the different levels of health care providers and between public and private health sectors in order to avoid gaps in medical care, and v) prioritizing investment in public and primary health services.

\section{Disclosure}

The authors report no conflicts of interest in this work.

\section{References}

1. Statista. Coronavirus (COVID-19) cases in Italy as of April 11, 2021, by region; 2020. Available from: https://www.statista.com/statistics/ 1099375/coronavirus-cases-by-region-in-italy/. Accessed April 14, 2021.

2. Boccia S, Ricciardi W, Ioannidis JPA. What other countries can learn from Italy during the COVID-19 pandemic. JAMA Intern Med. 2020;180(7):927-928. doi:10.1001/jamainternmed.2020.1447

3. Travaglino GA, Moon C. Explaining compliance with social distancing norms during the COVID-19 pandemic: the roles of cultural orientations, trust and self-conscious emotions in the US. Italy South Korea psyarXiv. 2020. doi:10.3389/fpsyg.2021.565845

4. Capalbo C, Aceti A, Simmaco M, et al. The exponential phase of the Covid-19 pandemic in central Italy: an integrated care pathway. Int J Environ Res Public Health. 2020;17(11):3792. doi:10.3390/ ijerph17113792
5. ISTAT. Available from: https://www.istat.it/it/files/2021/03/Report ISS_Istat_2020_5_marzo.pdf. Accessed May 21, 2021.

6. Plagg B, Oschmann J, Engl A, Piccoliori G, Conca A, Eisendle K. We're in this together: intergenerational health policies as an emerging public health necessity. Front Human Dyn. 2020;2:9. doi:10.3389/fhumd.2020.566705

7. Mauro M, Maresso A, Guglielmo A. Health decentralization at a dead-end: towards new recovery plans for Italian hospitals. Health Policy. 2017;121(6):582-587. doi:10.1016/j.healthpol.2017.04.003

8. World Health Organization. Available from: https://www.euro.who. int/_data/assets/pdf_file/0009/389844/Designed-report-2.pdf. Accessed May 21, 2021.

9. World Health Organization. Italy health system review. Available from: https://apps.who.int/iris/bitstream/handle/10665/141626/HiT16-4-2014-eng.pdf?sequence $=5 \&$ isAllowed=y. Accessed March 25, 2021.

10. Regione Lombardia. Fontana e Gallera: 202 milioni per investimenti in ospedali e IRCCS pubblici. [Fontana and Gallera: 202 million for investments in public hospitals and IRCCSs]. Available from: https://www. regione.lombardia.it/wps/portal/istituzionale/HP/lombardia-notizie /DettaglioNews/2019/11-novembre/18-24/fontana-gallera-202-milioniinvestimenti-irccs. Accessed March 20, 2021.

11. Kringos DS, Boerma WG, Hutchinson A, Saltman RB. Building primary care in a changing Europe. Case studies. WHO Regional Office for Europe; 2015.

12. Sanità domani; 2020. Available fom: https://sanitadomani.com/confontana-e-gallera-la-sanita-lombarda-e-leader/. Accessed March 20, 2021.

13. Rimmer A. Covid-19: GPs call for same personal protective equipment as hospital doctors. BMJ. 2020;368:m1055. PMID: 32169866. doi:10.1136/bmj.m1055

14. Alsnes IV, Munkvik M, Flanders WD, Øyane N. How well did Norwegian general practice prepare to address the COVID-19 pandemic? Family Med Commun Health. 2020;8(4):e000512. doi:10.1136/fmch-2020-000512

15. Houghton C, Meskell P, Delaney H, et al. Barriers and facilitators to healthcare workers' adherence with infection prevention and control (IPC) guidelines for respiratory infectious diseases: a rapid qualitative evidence synthesis. Cochrane Database Syst Rev. 2020;4(4): CD013582. PMID: 32315451; PMCID: PMC7173761. doi:10.1002/ 14651858.CD013582

16. Amerio A, Bianchi D, Santi F, et al. Covid-19 pandemic impact on mental health: a web-based cross-sectional survey on a sample of Italian general practitioners. Acta Bio-Medica. 2020;91(2):83-88.

17. FNOMCeO. Elenco dei Medici caduti nel corso dell'epidemia di Covid-19; 2020. [List of Doctors who died during the Covid-19 epidemic]. Available from: https://portale.fnomceo.it/elenco-dei-medicicaduti-nel-corso-dellepidemia-di-covid-19/. Accessed February 22, 2021.

18. Belingheri M, Paladino ME, Riva MA. Beyond the assistance: additional exposure situations to COVID-19 for healthcare workers. $J$ Hospital Infect. 2020;105(2):353. doi:10.1016/j.jhin.2020.03.033

19. Car J, Koh GC, Foong PS, Wang CJ. Video consultations in primary and specialist care during the covid-19 pandemic and beyond. BMJ. 2020;371. doi:10.1136/bmj.m3945

20. Danhieux K, Buffel V, Pairon A, et al. The impact of COVID-19 on chronic care according to providers: a qualitative study among primary care practices in Belgium. BMC Fam Pract. 2020;21(1):1-6. doi:10.1186/s12875-020-01326-3

21. Chudasama YV, Gillies CL, Zaccardi F, et al. Impact of COVID-19 on routine care for chronic diseases: a global survey of views from healthcare professionals. Diabetes Metab Syndr. 2020;14(5):965-967. doi:10.1016/j.dsx.2020.06.042

22. Lombardia Sociale. Il territorio abbandonato. [The abandoned territory]; 2020. Available from: http://www.lombardiasociale.it/2020/04/ 24/il-territorio-abbandonato/. Accessed February 20, 2021. 
23. Rawaf S, Allen LN, Stigler FL, Kringos D, Quezada Yamamoto H, van Weel C. Global forum on universal health coverage and primary health care. Lessons on the COVID-19 pandemic, for and by primary care professionals worldwide. Eur J General Practice. 2020;26 (1):129-133. doi:10.1080/13814788.2020.1820479

24. Nurse Times. Troppi codici bianchi nei pronto soccorso. [Too many white codes in emergency rooms]; 2019. Available from: https:// www.nursetimes.org/troppi-codici-bianchi-nei-pronto-soccorso-lalombardia-corre-ai-ripari/72671. Accessed March 20, 2021.

25. McNicholas A, Lennon D, Crampton P, Howden-Chapman P. Overcrowding and infectious diseases-when will we learn the lessons of our past? New Zealand Med J. 2000;113(1121):453.

26. Virtanen M, Terho K, Oksanen T, et al. Patients with infectious diseases, overcrowding, and health in hospital staff. Arch Intern Med. 2011;171(14):1296-1298. doi:10.1001/archinternmed.2011.313

27. Catena R, Holweg M. We need to relocate ICU patients out of covid-10 hotspots. Harvard business review. Available from: https:// hbr.org/2020/06/we-need-to-relocate-icu-patients-out-of-covid-19hotspots. Accessed September 15, 2021.

28. Manzoni P, Milillo C. Covid-19 mortality in Italian doctors. $J$ Infect. 2020;81(2):e106-e107. doi:10.1016/j.jinf.2020.05.034

29. Bedini AV. LA SALUTE AI TEMPI DI SARS-COV-2 Il Caso Lombardo. [HEALTH AT THE TIME OF SARS-COV-2 The Lombardy case]; 2020. Available from: https://www.nens.it/sites/default/files/doc\%20Covid-2a \%20edizione.pdf. Accessed March 20, 2021.

30. Berloto S, Notarnicola E, Perobelli E, Rotolo A. Available from: Italy: estimates of mortality of nursing home residents and staff linked to the COVID-19 pandemic. LTC responses to COVID-19. https://tccovid.org/wp-content/uploads/2020/06/Mortality_Italy-25June.pdf. Accessed March 7, 2021.

31. Il fatto quotidiano. Coronavirus - Fontana: 'Pazienti Covid in Rsa? Proposta dei tecnici. [Coronavirus - Fontana: 'Covid patients in nursing homes? Proposal by technicians]; 2020. Available from: https:// www.ilfattoquotidiano.it/2020/04/17/coronavirus-fontana-pazienticovid-in-rsa-e-stata-proposta-dei-tecnici-controllo-spettava-alleaziende-sanitarie/5772988/. Accessed March 20, 2021.

32. The world bank. Hospital beds (per 1.000 people) - Italy. Available from: https://data.worldbank.org/indicator/SH.MED.BEDS.ZS?end= 2012\&locations=IT\&start=1960\&view=chart. Accessed March 23, 2021.

33. Ministero della salute. Annuario Statistico del Servizio Sanitario Nazionale. [Statistical Yearbook of the National Health Service.]; 2017. Available from: http://www.salute.gov.it/imgs/C_17_pubblica zioni_2879_allegato.pdf. Accessed March 20, 2021.

34. Eurostat. Current healthcare expenditure; 2017. Available from: https://ec. europa.eu/eurostat/statistics-explained/index.php?title=File:Current_ healthcare_expenditure,_2017_SPS20.png. Accessed February 20, 2021.

35. Lega F, Mauri M, Prenestini A. L'ospedale tra presente e futuro: Analisi, diagnosi e linee di cambiamento per il sistema ospedaliero italiano. [The hospital between present and future: Analysis, diagnosis and directions for change in the Italian hospital system]. Egea Edizione Uni Bocconi; 2010.

Risk Management and Healthcare Policy

\section{Publish your work in this journal}

Risk Management and Healthcare Policy is an international, peerreviewed, open access journal focusing on all aspects of public health, policy, and preventative measures to promote good health and improve morbidity and mortality in the population. The journal welcomes submitted papers covering original research, basic science, clinical \& epidemiological studies, reviews and evaluations,
36. Nardi R, Arienti V, Nozzoli C, Mazzone A. Organizzazione dell'ospedale per intensità di cure: gli errori da evitare. [Hospital organisation by intensity of care: mistakes to avoid]. Italian J Med. 2012;6 (1):1-3. doi:10.4081/itjm.2012.1

37. Lahner E, Dilaghi E, Prestigiacomo C, et al. Prevalence of Sars-Cov2 infection in health workers (HWs) and diagnostic test performance: the experience of a teaching hospital in central Italy. Int $J$ Environ Res Public Health. 2020;17(12):4417. doi:10.3390/ijerph17124417

38. Glorioso V, Subramanian SV. Equity in access to health care services in Italy. Health Serv Res. 2014;49(3):950-970. doi:10.1111/14756773.12128

39. World Health Organization. State of health in the EU - Italy; 2017. Available from: https://www.euro.who.int/_data/assets/pdf_file/ 0008/355985/Health-Profile-Italy-Eng.pdf?ua=1. Accessed March 20, 2021.

40. Quercioli C, Messina G, Basu S, McKee M, Nante N, Stuckler D. The effect of healthcare delivery privatisation on avoidable mortality: longitudinal cross-regional results from Italy, 1993- 2003. J Epidemiol Commun Health. 2013;67(2):132-138. doi:10.1136/ jech-2011-200640

41. Assa J, Calderon C. Privatization and pandemic: a cross-country analysis of COVID-19 rates and health-care financing structures. Res Gate. 2020. doi:10.13140/RG.2.2

42. Austin KF, DeScisciolo C, Samuelsen L. The failures of privatization: a comparative investigation of tuberculosis rates and the structure of healthcare in less-developed nations, 1995-2010. World Dev. 2016;78:450-460. doi:10.1016/j.worlddev.2015.10.027

43. Finch WH, Hernández Finch ME. Poverty and Covid-19: rates of incidence and deaths in the United States during the first 10 weeks of the pandemic. Front Sociol. 2020;5:47. doi:10.3389/fsoc.2020.00047

44. Ahmed F, Ahmed NE, Pissarides C, Stiglitz J. Why inequality could spread COVID-19. Lancet Public Health. 2020;5(5):e240. doi:10.1016/S2468-2667(20)30085-2

45. Abrams EM, Szefler SJ. COVID-19 and the impact of social determinants of health. Lancet Respir Med. 2020;8(7):659-661. doi:10.1016/S2213-2600(20)30234-4

46. Johnson CK, Hitchens PL, Pandit PS, et al. Global shifts in mammalian population trends reveal key predictors of virus spillover risk. Proc Royal Soc B. 2020;287(1924):20192736. doi:10.1098/ rspb.2019.2736

47. OECD. Realising the full potential of primary health care; 2019. Available from: http://www.quotidianosanita.it/allegati/alle gato489982.pdf. Accessed 21 May, 2021.

48. World Health Organization. Ensuring collaboration between primary health care and public health services; 2018. Available from: https:// www.euro.who.int/_data/assets/pdf_file/0009/389844/Designedreport-2.pdf. Accessed May 25, 2021. 